\title{
What affects digitalization process in developing economies? An evidence from SMEs sector in Oman
}

\author{
Mansour Naser Alraja1, Muawya Ahmed Hussein ${ }^{2}$, Hanaa Mahmoud Sid Ahmed ${ }^{3}$ \\ ${ }^{1}$ Department of Management Information systems, College of Commerce and Business Administration, \\ Dhofar University, Oman \\ ${ }^{2}$ College of Commerce and Business Administration, Dhofar University, Oman \\ ${ }^{3}$ International Business Administration, Salalah College of Applied Sciences, Oman
}

\begin{tabular}{l}
\hline \hline Article Info \\
\hline Article history: \\
Received Dec 4, 2019 \\
Revised Apr 5, 2020 \\
Accepted Jul 12, 2020 \\
\hline
\end{tabular}

Keywords:

Digitization SMEs

Structural equation modeling (SEM)

Technological organizational and environmental (TOE)

model

\begin{abstract}
The main objective of this paper is to investigate the SMEs' leader perspective about the basic factors influencing the transformation into digitalization by SMEs they lead, using technological, organizational, and environmental (TOE) model. The data were collected from 61 SMEs leaders in Oman, to achieve the study objective TOE model has been adopted. Internal consistency and data normality, and factor analysis were implemented. Structural equation modeling (SEM) used to test the proposed hypotheses. The outcomes of SEM indicate that TOE factors are significantly affects the ability of SMEs to digitalize their business process. The study findings come in the context of Omani definition of SMEs. More, no control was made for industry type to which SMEs participants are belong. Leaders of SMEs should frame strategies to simplify the digital transformation of their enterprises and attempt to provide organizational and technological facilities that will smooth their digitalization which will improve SMEs capabilities, as well as, increasing the international competitiveness of the SMEs. To the best of the authors' knowledge, this study is one of the first that investigated the digital transformation among SMEs from the leaders' perspective in Oman.
\end{abstract}

This is an open access article under the CC BY-SA license.

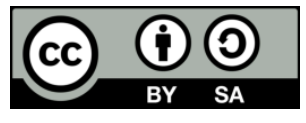

\section{Corresponding Author:}

Mansour Naser Alraja,

Department of Management Information systems, College of Commerce and Business Administration,

Dhofar University, Oman.

Email:malraja@du.edu.om

\section{INTRODUCTION}

Digital transformation (digitalization) is changed from being business support to being the business itself [1]. Digitalization reflect the process used to restructure companies, society, and even economies on a system level [2]. This process should not be understood as incorporating new technologies or upgrading the already used technology, but making a real change in the adopted business model [3]. Therefore, establishing this process is essential for business progression. Taking in consideration real business examples e.g. the drastic change how businesses mange the relation with customers was a result of advance in technology such social media. As a matter of fact, not only large companies, governments, and multinational organizations can do such transformation, but also small and medium-sized enterprises (SMEs) can adopt this process for transformation to create and gain the value of digitalization [2, 4].

Small and medium enterprises (SMEs) are considered the backbone of the industry as they play an important role in the economy [5,6]. As much as the participation of SMEs to economy of any country is larger, then the economic feature of this definite country will be more powerful [7]. Being the investment in information technology (IT) mostly support and enable the innovation [8]. Also, research proved that 
the well-developed and designed technology (such as websites) are significantly affected the users emotionally [9]. Therefore, to increase this participation, SMEs began using electronic technology in their business $[10,11]$. Meanwhile, not like big businesses, SMEs couldn't invest large sum of capital on using digital technology [12]. Thereby, adopting technology and digitalizing SMEs activities wasn't that easily, it was lower than the predicted plans [13, 14]. Digitalizing SMEs activities have been restricted by interior knowledge, technology capability, enterprise size, inadequate funds, and lack of resources [13, 15-20].

Whatever those restrictions, many researchers studied the factors influencing the adoption of electronic technology among SMEs from different perspectives. In their study [21] identified three factors that may affect the electronic data interchange within the small organization. Further, [22] reviewed the previous studies to identify factors that help to distinguish between adopters and non-adopters of e-commerce. However, the selected variables pointed out that only $19.4 \%$ of the variance in the e-commerce adoption/non-adoption in small and medium sized businesses can be explained by the discriminant function (i.e. this mix does not rely on accepted model so maybe there was direct or indirect conflict between some of its component). More, in their study [23] used diffusion of innovations (DOI) model to analyze the factors that influence the ICT adoption by SMEs in Colombia, and they suggested using other models for technology adoption among SMEs. Authors [24] used modified model of technology acceptance to analyzes the adoption and diffusion of smart learning within SMEs from the human resource development managerial perspective, and they compared it with large enterprises. Furthermore, to estimate either small or medium sized enterprises are more expected to adopt enterprise systems (e-procurement, supply chain management systems, customer relationship management system, and enterprise resources planning). Studding all those systems in the same time made it difficult to differentiate between factors that affect each single system [25].

However, statistically many studies tested the factors influencing the adoption of information technology among SMEs using only the regression analysis which has many limitations regarding the possibility of a hierarchical relationship of the independent variables, i.e. will not investigate interaction among the variables [5, 10, 25, 26]. In addition, [27] studied how in less developed and developing countries, the achievement of digitalization is affected by organization readiness and readiness of outside environment in IT handling. However, in the Omani context, Oman is characterized by big geographical area and small population. The telecommunication infrastructure including land lines and/or mobile, and Internet services are available to more than $80 \%$ of the population, so the adoption of digital technology by SMEs in Oman is expected. Oman as one of the GCC countries is of no exception heavily dependent on oil. The instability of oil prices enforces the country to look into the way out through the diversification of the economy for sustainable development.

Consequently, the main contribution of this paper is trying to fill the raised gap by reviewed studies and owing to the fact that the degree to which SMEs in Oman can really transform into digitalization and the factors that affect this transformation is uncertain. Therefore, researchers are attempting to identify what are the main factors that may affect the process of digitalization among Omani SMEs, taking in consideration many points (1) avoid the hidden discrepancy between the variables by using widely accepted model to predict the digital transformation within Omani SMEs from those enterprises leaders' perspective, therefore the Technological, Organizational, and Environmental (TOE) model was adopted. (2) Despite the exploratory nature of the most previous studies which helps in identifying the relation between variables, but it does not confirm this relation. In this study confirmatory hypotheses have been generated. Therefore, technique of Structural equation modelling (SEM) will applied to confirm the relation and identifying the effect of technological, organizational, and environmental factors on transformation into digitalization by SMEs in Oman. More, (3) eliminate the confusion by focusing on digital transformation instead of studying the adoption of many electronic systems. Therefore, the main objective of this paper is to scrutinize the opinions of SMEs' leaders in Oman about the basic factors influencing the transformation into digitalization by SMEs they lead, using technological, organizational, and environmental model.

\section{LITERATURE REVIEW}

To study how individuals behave toward new technology many studies has been conducted using different technology acceptance models for instance TAM and UTAUT [28-33]. While, within initiations (such SMEs) many other models maybe used. Technological, organizational, and environmental framework (TOE) model has been used to propose a perception-based model for electronic data interchange among small business [34]. Making a real change in the SMEs business model by improving their process digitalization will positively affect the range of operations that can be run by the SMEs, and raise their productivity and profitability. In the same context, in this study the essential variables that may affect the digitalization process of SMEs, as presented in Figure 1 proposed research model, are taken out from the technology, organization and environment (TOE) model [35]. 


\subsection{Technological}

This illustrate to which level IT is used by SMEs [36]. However, technology considered a vital element for successful digitalization adoption [34]. As a driver for digitalization adoption this important factor consist of technologies infrastructure, employees experience in context of technology, and know how to use and implement this technology in dealing with customers [37, 38]. More, if the level of used IT resources in the enterprises is sufficient this will increase the SMEs ability to successfully embracing IT and transform their process and activities into digital business [39-42].

\subsection{Organizational}

The large scope of the enterprise leads to increase the internal, search, and storage costs [43]. Contrariwise, the investment in technology commensurate with firm scope, since the firms digitalization will help enterprises to decrease their internal, search, and storage costs [37, 44]. More, a very important determinant regarding digitalization adoption is the firm size [45]. The previous studies mentioned that the large firms are more candidate to undertake digitalization rather than small firms [46]. Furthermore, the expected pros and cons have a considerable effect in digitalization adoption [38, 42, 47]. Anywise, the large firms in contrast to the small firms, have a big bureaucracy which it may lead to slow down the process of decision-making, and make the coordination and collaboration difficult to be achieved [46]. As the work within the SMEs has its own beliefs and practices, so if the used IT is proportionate with those beliefs and practices, the ability of SMEs will be increased to transform their process and activities into digital business [36].

\subsection{Environmental}

The level of internet permeation among people is a significant indication for firms to digitalize their work, which is recognized as an indicator of prospective customers [37, 48]. Moreover, the context in which the firm exist and the power of competitors, may considered an important driver of digitalization adoption by the firms [49-51]. In this study environmental factor refers to that context in which the SMEs growing in, which include multiple stakeholders who are able to influence on SMEs either to support the SMEs transformation into digital business or blocking the technological innovation [52-54]. Relying on the above discussed literature the researchers suggest the following hypotheses.

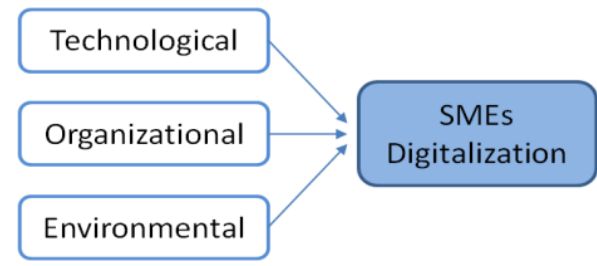

Figure 1. Proposed research model

H1: The digitalization of SMEs is significantly influenced by technological factors.

$\mathrm{H} 2$ : The digitalization of SMEs is significantly influenced by organizational factors.

H3: The digitalization of SMEs is significantly influenced by environmental factors.

\section{RESEARCH METHOD}

The requested data has been collected using a questionnaire designed for the purpose of investigating the influence of technological, organizational, and environmental factors on the SMEs digitization in Omani context. The study instrument was developed based on validated studies e.g. [37, 39, 55, 56], some changes has been made to be consist with the study environment. The participants were asked not to mention anything which may lead to reveal their personality, therefore, to help them easily answering the questionnaire we declared the purpose of the study, instructions for filling the questionnaire and ensuring the privacy and confidentiality of the participants. The questionnaire includes two portions: (1) SMEs profile and (2) adopted variables. All the items that associated with the adopted variables were framed on 5-point Likert scale. To check the understanding and clarity of questions in addition to improve the questions, a pilot study was conducted comprised of 6 SMEs leaders, depending on their feedback some items were modified or deleted. Subsequent to reviewing the questionnaire, 75 copies were distributed to the leaders of the SMEs in Sultanate of Oman, we were able to return 68 questionnaires, out of those returned questionnaires 7 copies were 
removed from the analysis because of giving the same answer to all items and/or some questions left without answers. Thereby, the number of the valid questionnaires for analysis was 61 questionnaires. Since the data has been collected by a questionnaire, so we have to confirm the internal consistency of construct and measures validity, for that reason, factor analysis and reliability test were conducted to meet this purpose. Moreover, to test the data normality a skewness test was implemented. Whilst, hypotheses have been tested using the structural equation modelling for analysing the path from technological, organizational, and environmental factors to SMEs digitalization

\section{RESULTS AND ANALYSIS}

Table 1 shows the results pertained to means, standard deviation, skewness, and correlations for the study variables. checking the skewness values, which represent the data normality, all of them are exist in the acceptable range $(-2$ to +2$)$ according to $[57,58]$. The responses of the participants were to some extent close as the mean range between 3.4-4.19 with S.D. between 0.74-0.92. From the same table the correlation matrix shows that technological, organizational, and environmental factors are significantly and positively related to SMEs digitalization.

Table 1. Means, standard deviation, skewness, correlations

\begin{tabular}{llccccc}
\hline & \multicolumn{1}{c}{ Scales } & Mean (SD) & $\begin{array}{c}\text { Skewness } \\
\text { Std. Error=(.306) }\end{array}$ & 1 & 2 & 3 \\
\hline $\mathrm{O}$ & Organizational factors & $3.5779(.76)$ & -.975 & 1 & & \\
$\mathrm{E}$ & Environmental factors & $3.4303(.74)$ & -.838 & $.420^{* *}$ & 1 & \\
$\mathrm{~T}$ & Technological factors & $3.5597(.77)$ & -.181 & $.401^{* *}$ & .182 & 1 \\
& Digitalization of SMEs & $4.1885(.92)$ & -1.696 & $.647 * *$ & $.547^{* *}$ & $.467 * *$ \\
\hline
\end{tabular}

\subsection{Reliability test}

Furthermore, for internal consistency, the study instrument was tested utilizing Cronbach's coefficient alpha. As shown in Table 2 the value of Cronbach's coefficient alpha for the adopted variables varied between (.752) for the technological factor, (.762) for the environmental factor, (.883) for the organizational factor, and (.899) for the SMEs' digitization

Table 2. Exploratory factor analysis and reliability test

\begin{tabular}{|c|c|c|c|c|c|c|c|}
\hline \multicolumn{6}{|c|}{ Rotated component matrix } & \multirow{2}{*}{ Variables } & \multirow{2}{*}{ Cronbach's value } \\
\hline & & & & & & & \\
\hline O8 & .825 & E2 & .781 & T15 & .845 & $\mathrm{~T}$ & .752 \\
\hline O6 & .824 & E3 & .740 & $\mathrm{~T} 13$ & .764 & $\mathrm{O}$ & .883 \\
\hline $\mathrm{O} 7$ & .789 & E1 & .738 & $\mathrm{~T} 12$ & .708 & $\mathrm{E}$ & .762 \\
\hline $\mathrm{O} 10$ & .750 & E4 & .700 & $\mathrm{~T} 14$ & .611 & SMEsD & .899 \\
\hline O5 & .745 & & & & & & \\
\hline O9 & .637 & & & & & & \\
\hline O11 & .626 & & & & & & \\
\hline
\end{tabular}

\subsection{Factor analysis}

To inspect the validity of construct, an explorative analysis has been utilized is factor analysis, and the adopted method was Principal Components, meanwhile, the method of rotation was Varimax. Also, the validation level for the items load should be 0.40 [59-61]. Table 2 illustrates that all the underlying constructs of the organizational factor were loaded at component 1. More, the items coefficients of the organizational factor are extended from (.626) to (.825). While, all the underlying constructs of the environmental factor were loaded at component 1 . More, the items coefficients of the environmental factor are extended from (.700) to (.781). Whilst, all the underlying constructs of the technological factor were loaded at component 1 . More, the items coefficients of the technological factor are extended from (.611) to (.845). The results of the used explorative analysis illustrate that the items loaded duly in the construct discriminate validity, this result confirms that the collected data is valid.

\subsection{Structure equation model}

The results of SEM are for three independent variables (technological factors, organizational factors, and environmental factors), and one (1) dependent variable (digitalization of SMEs). The study model has 
been tested using structural equation model using AMOS v25 Figure 2 represent the hypothesized path model. The following Table 3 illustrate that the study model has a good fit to the observed data. As the $\mathrm{X} 2 / \mathrm{df}=1.345<5, \mathrm{RMR}=0.075<0.08$ and very close to 0 than $1, \mathrm{NFI}=0.733<1, \mathrm{CFI}=0.93>0.90$. Table 4 summarize the supported paths, i.e. all the suggested hypotheses are accepted.

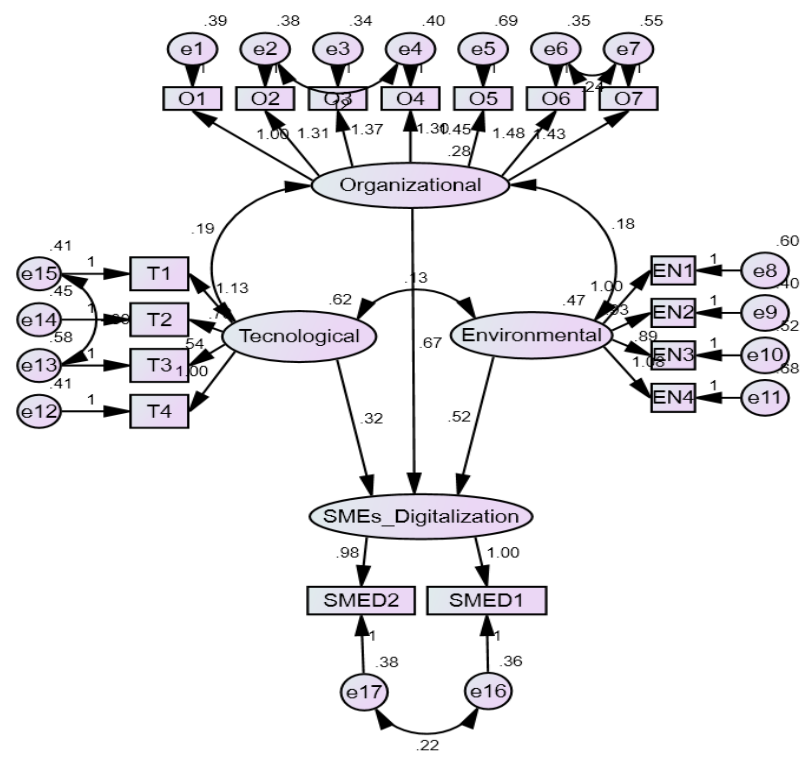

Figure 2. Structure equation model

Table 3. Model fit Indices

\begin{tabular}{cccccc}
\hline Models & CMIN/DF & RMR & NFI & CFI & RMSEA \\
\hline Model 1 & 1.345 & .075 & .87 & .926 & .075 \\
\hline
\end{tabular}

Note: $\mathrm{CMIN} / \mathrm{DF}=\mathrm{Chi}$-square/degree of freedom ratio $(1.00<\mathrm{CMIN} / \mathrm{DF}<5.00)$; RMR=Root mean square residual (RMR $<0.08)$ the smaller the RMR is the better, with a value of .08 or less being indicative of an acceptable model, $\mathrm{NFI}=$ Normed fit index $(0.90<\mathrm{NFI}<1.00)$; CFI=Comparative fit index $(0.90<\mathrm{CFI}<1.00)$; RMSEA=Root mean square of approximation (RMSEA $<0.08)$

Table 4. Hypotheses testing

\begin{tabular}{|c|c|c|c|c|}
\hline S. No & Hypothesis & Structural Path & St.d Reg. weights & Results \\
\hline 1 & $\begin{array}{l}\text { Ho1: the digitalization of SMEs is significantly influenced } \\
\text { by technological factors. }\end{array}$ & $\begin{array}{l}\text { Technological SMEs } \\
\text { Digitalization } \stackrel{ }{\longrightarrow}\end{array}$ & $\begin{array}{l}0.338 * \\
\text { Significant }\end{array}$ & Supported \\
\hline 2 & $\begin{array}{l}\text { Ho2: the digitalization of SMEs is significantly influenced } \\
\text { by organizational factors. }\end{array}$ & $\begin{array}{l}\text { Organizational SMEs } \\
\text { Digitalization } \stackrel{ }{\longrightarrow}\end{array}$ & $\begin{array}{l}0.475 * * \\
\text { Significant }\end{array}$ & Supported \\
\hline 3 & $\begin{array}{l}\text { Ho2: the digitalization of SMEs is significantly influenced } \\
\text { by environmental factors. }\end{array}$ & $\begin{array}{l}\text { Environmental SMEs } \\
\text { Digitalization } \stackrel{ }{\Longrightarrow}\end{array}$ & $\begin{array}{l}0.469 * * \\
\text { Significant }\end{array}$ & Supported \\
\hline
\end{tabular}

\section{DISCUSSION}

The essential aim of current paper is to identify what are the main factors that may affect the process of digitalization among Omani SMEs, using the technological, organizational, and environmental model. Further, the technique of structural equation modelling was applied to confirm the relation and identifying the effect of those factors on transformation into digitalization by SMEs in Oman. From the demographic point of view, most of the SMEs leaders are male $80.3 \%$ which indicate the innovative and enterprising character of the males in the region in the expansion of the SMEs sector, but here this result should be interpret in its cultural dimension within the Omani context as this dimension still restrict the female to start their own business even with the great support and encouragement from the government. Around $77.4 \%$ of the respondents have a high academic potentiality to develop the SMEs, and most of them are young. Moreover, the number of employees was between 2 to 20 . Further, $70.5 \%$ of the companies are using more than one component of digital technology. 
On the other hand, to check the hypothesis, the outcomes of the structural equation modelling indicate that organizational, environmental, and technological factors are significant where standard regression weights for technological factors $=0.338$, organizational factors $=0.475$, and environmental factors $=0.469$. More, all the calculated values were significant at $\mathrm{P}<0.05$ significant level. This denotes that organizational, environmental, and technological factors significantly affect the ability of SMEs to digitalize their business. These results are a perfect symptom of the influence of organizational, environmental, and technological on SMEs ability to digitalize their process and activities. These findings are in match with the earlier results and findings in the literature that the sufficient level of used technology resources by SMEs helps those enterprises to digitalize their processes [39-42]. In addition, compatible beliefs and practices with the used technology resources, increase the SMEs ability for digital transformation [36]. Furthermore, the industry, in which SMEs operates, influences the SMEs ability to transform into digital technologies [52-54, 62].

When the factors that affect the adoption of digital technologies are known, they will assist in framing policies to advance digital technologies adoption level. Therefore, managers of SMEs should frame strategies and policies that will simplify the digital transformation of their enterprises, because of its prospective role in improving companies and growth performance. While, SMEs owners should attempt to provide organizational and technological facilities that will smooth their digitalization as substitutes to do most SME transactions over the internet which will improve SMEs competitiveness. Moreover, for increasing the international competitiveness, SMEs owners should invest in digital technology and its components because it has been proven that it is significantly influencing the enterprise performance, as well as, they have to take in consider the most support of stakeholders who will help their SMEs to transform into the digital business. In conclusion organizational, environmental, and technological factors have a positive and significant effect on the SMEs' digitization.

\section{CONCLUSION}

This study attempted to investigate the perspective of SMEs' leaders about the influence of the main constructs of TOE model on SMEs Readiness to transform all/some processes or activities into digital technology (digitalization) from the point of view of those enterprises' leaders. Further, the structural equation modeling was used to test the study hypotheses and analyzing the path from technological, organizational, and environmental factors to SMEs digitalization.

Furthermore, the study revealed that all TOE constructs are significant at $\mathrm{P}<0.05$. This means the factors of the adopted model significantly affect the ability of SMEs to digitalize their business process or activities. Moreover, this research takes part in growing body of knowledge for both SMEs leaders and digitalization embrace among this type of enterprises in many ways.

First, this paper tried to add more understanding of digital technology and how it can be used to create competitive advantage. Second, to the best of the authors' knowledge, this study is one of the first that investigated the digital transformation among SMEs from the leaders' perspective using the SEM. However, as all other studies this research also has some limitation and future directions. First, the definition of SMEs is differing from country to another, thereby our findings should be interpreted in the context of Omani definition of SMEs. This point makes it very difficult to compare our findings with others conducted outside of Oman, which limits the reliability of results generalization on international level. Future studies may try to conduct cross-country taking in consideration the adopted criteria in defining among group of countries. Second, even though, we targeted the leaders of the SMEs, this makes the sample size relatively small. Therefore, the subsequent studies should consider this point and try to strength their result by size augmentation of the sample. Third, in this paper, no control was made for industry type to which SMEs are belonging. Thus, the model might be tested for a chosen industry or doing comparison study between SMEs to identify the extent of digitalization depending on industry type. However, a replication done in a developing country in general or in GCC (as Oman member of GCC) will provide scientific data for comparison between levels of digitalization among SMEs within those countries.

\section{REFERENCES}

[1] C. Louw and C. Nieuwenhuizen, "Digitalization strategies for SMEs: A cost vs. skill approach for website development," Journal African Journal of Science, Technology, Innovation and Development, vol. 12, no. 2, pp. 195-202, Jul. 2019.

[2] H. Bouwman, S. Nikou, and M. de Reuver, "Digitalization, business models, and SMEs: How do business model innovation practices improve performance of digitalizing SMEs?," Telecommunications Policy, vol. 43, no. 9, p. 101828, May 2019.

[3] C. Loebbecke and A. Picot, "Reflections on societal and business model transformation arising from digitization 
and big data analytics: A research agenda," The Journal of Strategic Information Systems, vol. 24, no. 3, pp. 149-157, Sep. 2015.

[4] A. Bharadwaj, O. A. El Sawy, P. A. Pavlou, and N. Venkatraman, "Digital business strategy: Toward a next generation of insights," MIS Quarterly, vol. 37, no. 2, pp. 471-482, 2013.

[5] S. Z. Ahmad, A. R. Abu Bakar, T. M. Faziharudean, and K. A. Mohamad Zaki, "An empirical study of factors affecting e-commerce adoption among small-and medium-sized enterprises in a developing country: evidence from Malaysia," Journal Information Technology for Development, vol. 21, no. 4, pp. 555-572, 2014.

[6] A. S. Saleh and N. O. Ndubisi, "An evaluation of SME development in Malaysia," International Review of Business Research Papers, vol. 2, no. 1, pp. 1-14, 2006.

[7] S. Sarosa, "The Information technology adoption process within Indonesian Small and medium enterprises certificate of authorship/originality," Thesis, Faculty of Information Technology. University of Technology Sydney, 2007.

[8] A. Scupola, "The relation between innovation sources and ICT roles in facility management organizations," Journal of Facilities Management, vol. 12, no. 4, pp. 368-381, Aug. 2014.

[9] P. Turumogan, A. Baharum, I. Ismail, N. A. Mohamed Noh, N. S. Ab Fatah, and N. A. Mat Noor, "Evaluating users' emotions for Kansei-based Malaysia higher learning institution website using Kansei checklist," Bulletin of Electrical Engineering and Informatics, vol. 8, no. 1, pp. 328-335, Mar. 2019.

[10] S. S. Alam, M. Y. Ali, and M. F. M. Jani, "An Empirical study of factors affecting electronic commerce adoption among SMEs in Malaysia," Journal of Business Economics and Management, vol. 12, no. 2, pp. 375-399, 2011.

[11] S. Subba Rao, G. Metts, and C. A. Mora Monge, "Electronic commerce development in small and medium sized enterprises," Business Process Management Journal, vol. 9, no. 1, pp. 11-32, Feb. 2003.

[12] C. M. Parker and T. Castleman, "New directions for research on SME-eBusiness: Insights from an analysis of journal articles from 2003 to 2006," Journal of Information Systems and Small Business, vol. 1, no. 1-2, pp. 21-40, 2007.

[13] P. Dharmalingam and G. Kannabiran, "Determinants of basic IT adoption by auto ancillary SMEs in India," The IUP Journal of Information Technology, vol. 7, no. 1, pp. 58-75, 2011

[14] J. Hashim, "Learning barriers in adopting ICT among selected working women in Malaysia," Gender in Management, vol. 23, no. 5, pp. 317-336, Jul. 2008.

[15] D. S. Bajwa, L. F. Lewis, G. Pervan, and V. S. Lai, "The adoption and use of collaboration information technologies: international comparisons," Journal of Information Technology, vol. 20, no. 2, pp. 130-140, 2005.

[16] L. Cui, C. Zhang, C. Zhang, and L. Huang, "Exploring IT adoption process in Shanghai firms," Journal of Global Information Management, vol. 16, no. 2, pp. 1-17, 2008.

[17] X. Duan, H. Deng, and B. Corbitt, "Evaluating the critical determinants for adopting e-market in Australian smalland-medium sized enterprises," Management Research Review, vol. 35, no. 3/4, pp. 289-308, Mar. 2012.

[18] R. A. Jones, N. L. Jimmieson, and A. Griffiths, "The impact of organizational culture and reshaping capabilities on change implementation success: The mediating role of readiness for change," Journal of Management Studies, vol. 42, no. 2, pp. 361-386, Mar. 2005.

[19] M. Levy and P. Powell, "Strategies for growth in SMEs: The Role of information and information sytems," Butterworth-Heinemann, 2004.

[20] R. C. MacGregor, "Factors associated with formal networking in regional small business: some findings from a study of Swedish SMEs,” Journal of Small Business and Enterprise Development, vol. 11, no. 1, pp. 60-74, 2004.

[21] C. L. Iacovou, I. Benbasat, and A. S. Dexter, "Electronic data interchange and small organizations: Adoption and impact of technology," MIS Quarterly, vol. 19, pp. 465-485, Dec. 1995.

[22] J. M. Pearson and E. E. Grandon, "An empirical study of factors that influence e-commerce adoption/non-adoption in small and medium sized businesses," Journal of Internet Commerce, vol. 4, no. 4, pp. 1-21, Dec. 2005.

[23] C. Osorio-Gallego, J. Londoño-Metaute, and E. López-Zapata, "Analysis of factors that influence the ICT adoption by SMEs in Colombia," Intangible Capital, vol. 12, no. 2, pp. 666-698, Apr. 2016.

[24] J. Lee, M. Choi, and H. Lee, "Factors affecting smart learning adoption in workplaces: Comparing large enterprises and SMEs," Information Technology and Management, vol. 16, no. 4, pp. 291-302, Dec. 2015.

[25] B. Ramdani, P. Kawalek, and O. Lorenzo, "Predicting SMEs' adoption of enterprise systems," Journal of Enterprise Information Management, vol. 22, no. 1, pp. 10-24, Feb. 2009.

[26] S. Chong, "An empirical study of factors that influence the extent of deployment of electronic commerce for smalland medium-sized enterprises in Australia," Journal of Theoretical and Applied Electronic Commerce Research, vol. 1, no. 2, pp. 45-57, 2006.

[27] A. Molla, "The Impact of eReadiness on eCommerce Success in Developing Countries: Firm-Level Evidence," Development Informatics, Working Paper Seties, Institute for Development Policy and Management, no. 18, 2004. [Online]. Available at: http://idpm.man.ac.uk/. Accessed: 01-Oct-2017.

[28] D. Arvie and A. R. Tanaamah, "Technology acceptance model for evaluating IT of online based transportation acceptance: A case of GO-JEK in Salatiga," TELKOMNIKA Telecommunication, Computing, Electronics and Control, vol. 17, no. 2, pp. 667-675, Apr. 2019.

[29] P. Surendran, "Technology acceptance model: A survey of literature," International Journal of Business and Social Research, vol. 2, no. 4, pp. 175-178, 2012.

[30] M. Zhou, L. Zhao, N. Kong, K. S. Campy, S. Qu, and S. Wang, "Factors influencing behavior intentions to telehealth by Chinese elderly: An extended TAM model," International Journal of Medical Informatics, vol. 126, pp. 118-127, Jun. 2019.

[31] Q. Cao and X. Niu, "Integrating context-awareness and UTAUT to explain Alipay user adoption," International

What affects digitalization process in developing economies? An evidence... (Mansour Naser Alraja) 
Journal of Industrial Ergonomics, vol. 69, pp. 9-13, Jan. 2019.

[32] V. Venkatesh, M. G. Morris, G. B. Davis, and F. D. Davis, "User acceptance of information technology: Toward a unified view," MIS Quarterly, vol. 27, no. 3, pp. 425-478, 2003.

[33] F. D. Davis, "Perceived usefulness, perceived ease of use, and user acceptance of information technology," MIS Quarterly, vol. 13, pp. 319-340, Sep. 1989.

[34] K. K. Y. Kuan and P. Y. K. Chau, "A perception-based model for EDI adoption in small businesses using a technology-organization-environment framework," Information \& Management, vol. 38, no. 8, pp. 507-521, 2001.

[35] L. G. Tornatzky, M. Fleischer, and A. K. Chakrabarti, "The processes of technological innovation," Lexington Books, Lexington MA, 1990

[36] P-F. Hsu, K. Kraemer, and D. Dunkle, "Determinants of e-business use in U.S. firms," Journal International Journal of Electronic Commerce, vol. 10, no. 4, pp. 9-45, Jun. 2006.

[37] K. Zhu, K. Kraemer, S. Xu, and K. L. Kraemer, "A cross-country study of electronic business adoption using the technology-organization environment framework," ICIS 2002 Proceedings, pp. 337-348, 2002.

[38] M. Pan and W.-Y. Jang, "Determinants of the adoption of enterprise resource planning within the technology organization environment framework: taiwan's communications industry," Journal of Computer Information Systems, vol. 48, no. 3, pp. 94-102, 2008.

[39] M. N. Alraja and N. M. M. Malkawi, "E-Business adoption in banking sector: Empirical study," Indian Journal of Science and Technology, vol. 8, no. 27, pp. 19-25, 2015.

[40] S. Wang and W. Cheung, "E-business adoption by travel agencies: Prime candidates for mobile e-business," Journal International Journal of Electronic Commerce, vol. 8, no. 3, pp. 43-63, 2004.

[41] A. J. Morrison and B. E. M. King, "Small tourism businesses and e-commerce: Victorian tourism online," Tourism and Hospitality Research, vol. 4, no.2, pp. 104-115, 2002.

[42] H-F. Lin and S-M. Lin, "Determinants of e-business diffusion: A test of the technology diffusion perspective," Technovation, vol. 28, no. 3, pp. 135-45, Mar. 2008.

[43] S. Chopra and P. Meindl, "Supply chain management-strategy, planning, and operation," Prentice Hall, 2001.

[44] A. Barua, P. Konana, A. B. Whinston, and F. Yin, "Assessing Internet enabled business value: An exploratory investigation," MIS Quarterly, vol. 28, no. 4, pp. 585-620, 2004.

[45] G. Lee and W. Xia, "Organizational size and IT innovation adoption: A meta-analysis," Information \& Management, vol. 43, no. 8, pp. 975-985, Dec. 2006.

[46] T. Oliveira and M. F. Martins, "Firms patterns of e-business adoption: Evidence for the European union-27," Electronic Journal of Information Systems Evaluation, vol. 13, no. 1, pp. 47-56, 2010.

[47] J. L. Gibbs and K. L. Kraemer, "A cross-country investigation of the determinants of scope of e-commerce use: An institutional approach," Electronic Markets, vol. 14, no. 2, pp. 124-137, 2004.

[48] K. Zhu, K. Kraemer, and S. Xu, "Electronic business adoption by European firms: a cross-country assessment of the facilitators and inhibitors," European Journal of Information Systems, vol. 12, no. 4, pp. 251-268, 2003.

[49] G. Battisti, H. Hollenstein, P. Stoneman, and M. Woerter, "Inter and intra firm diffusion of ict in the United Kingdom (UK) and Switzerland (CH) an internationally comparative study based on firm-level data," Journal Economics of Innovation and New Technology, vol. 16, no. 8, pp. 669-687, 2007.

[50] R. R. Dholakia and N. Kshetri, "Factors impacting the adoption of the internet among SMEs," Small Business Economics, vol. 23, no. 4, pp. 311-322, Nov. 2004.

[51] N. Al-Qirim, "The adoption of eCommerce communications and applications technologies in small businesses in New Zealand," Electronic Commerce Research and Applications, vol. 6, no. 4, pp. 462-473, Dec. 2007.

[52] B. Ramdani, O. Lorenzo, and P. Kawalek, "Information systems innovations adoption and diffusion among SMEs," International Journal of E-Adoption, vol. 1, no. 1, pp. 33-45, 2009.

[53] R. Angeles, "Using the technology-organization-environment framework for analyzing nike's 'considered index' green initiative, a decision support system-driven system,” Journal of Management and Sustainability, vol. 4, no. 1, pp. 96-113, 2014.

[54] J. Baker, "The technology-organization-environment framework," Information Systems Theory, pp. 231-245, 2012.

[55] H. Gangwar, H. Date, and R. Ramaswamy, "Understanding determinants of cloud computing adoption using an integrated TAM-TOE model," Journal of Enterprise Information Management, vol. 28, no. 1, pp. 107-130, 2015.

[56] Y.-M. Wang, Y.-S. Wang, and Y.-F. Yang, "Understanding the determinants of RFID adoption in the manufacturing industry," Technological Forecasting and Social Change, vol. 77, no. 5, pp. 803-815, Jun. 2010.

[57] F. J. Gravetter and L. B. Wallnau, "Essentials of statistics for the behavioral sciences, $8^{\text {th }}$ edition," Cengage Learning, 2013.

[58] M. N. Alraja and M. A. S. Kashoob, "Transformation to electronic purchasing: an empirical investigation," TELKOMNIKA Telecommunication, Computing, Electronics and Control, vol. 17, no. 3, pp. 1209-1219, 2019.

[59] Y. K. Dwivedi, J. Choudrie, and W.-P. Brinkman, "Development of a survey instrument to examine consumer adoption of broadband," Industrial Management \& Data Systems, vol. 106, no. 5, pp. 700-718, 2006.

[60] L. Carter, L. Schaupp and A. Evans, "Antecedents to e-file adoption: The U.S. perspective," Proceedings of the 41 st Annual Hawaii International Conference on System Sciences (HICSS 2008), pp. 216-216, 2008.

[61] D. Straub, M.-C. Boudreau, D. Gefen, "Validation guidelines for IS positivist research," Communications of the Association for Information Systems, vol. 13, no. 1, pp. 380-427, 2004.

[62] N. Levenburg, S. R. Magal, and P. Kosalge, "An exploratory investigation of organizational factors and e-business motivations among SMFOEs in the US," Journal Electronic Markets, vol. 16, no. 1, pp. 70-84, 2006. 